\title{
EFFECT OF PESTICIDES ON THE GROWTH, PHOTOSYNTHETIC OXYGEN EVOLUTION AND NITROGEN FIXATION OF WESTIELLOPSIS PROLIFICA
}

\author{
SIBA P. ADHIKARY* \\ P.G. Department of Botany, Utkal University, Bhubaneswar-751004, \\ Orissa, India
}

(Received August 17, 1989)

\begin{abstract}
We examined the effect of the pesticides Furadan (Carbofuran, 3\%), Sevin (Carbaryl, 50\%), Rogor (Dimetnoate, 30\% EC) and Endotaf (Endosulfan, $35 \%$ EC) on the survival, growth, photosynthetic oxygen evolution and nitrogen fixation of the cyanobacterium Westiellopsis prolifica. Lower concentrations of the carbamate and organophosphate pesticides (10 ppm) increased the growth and nitrogen fixation while higher concentrations $(>20 \mathrm{ppm}$ ) had an inhibitory effect. The organochlorine pesticide Endotaf was toxic even at $10 \mathrm{ppm}$. Survivability and nitrogen fixation of the cyanobacterium was reduced to 72 and $93 \%$ respectively in the presence of $100 \mathrm{ppm}$ of Endotaf. An exposure of the filaments to over $100 \mathrm{ppm}$ of Furadan, Sevin or Rogor caused about a $40 \%$ inhibition of the photosynthetic oxygen evolution. Endotaf was more toxic than the other pesticides. Oxygen evolution was totally suppressed after incubation of the organism with over $250 \mathrm{ppm}$ of Endotaf; there was similar suppression of $\mathrm{O}_{2}$ evolution on treatment with more than $500,1,000$, and $1,500 \mathrm{ppm}$ of Rogor, Sevin and Furadan respectively.
\end{abstract}

Various cyanobacterial species occur abundantly in rice-fields of tropical and sub-tropical countries, whose agricultural technologies involve extensive use of pesticides for selective elimination of pests of rice crops $(1,3,8,14)$. Therefore, the indiscriminate use of pesticides may be causing adverse effects on these rice-field nitrogen-fixing cyanobacteria which have a direct influence on the total productivity. A number of pesticides have been tested for their toxicity in microbiological systems $(6,9,12,13)$. Four commonly used pesticides-Furadan (Carbofuran, 3\%), Sevin (Carbaryl, 50\%), Rogor (Dimetnoate, 30\% EC) and Endotaf (Endosulfan, 35\%

* Address reprint requests to: Dr. Siba P. Adhikary, Lecturer, Department of Botany, Utkal University, Vani Vihar, Bhubaneswar-751004, Orissa, India. 
EC), applied extensively to control rice pests of this region, have been tested in the present work to determine their effect on the survivability, growth, photosynthetic oxygen evolution and nitrogen fixation of a locally isolated rice-field cyanobacterium Westiellopsis prolifica Janet.

\section{MATERIALS AND METHODS}

A pure culture of the rice-field cyanobacterium Westiellopsis prolifica Janet was used as the experimental organism. The cyanobacterium was grown in Allen and Arnon's nitrogen free medium (2) with micronutrients as used by Fogg (5). The cultures were maintained at $28 \pm 2^{\circ} \mathrm{C}$ under $2,400 \mathrm{~lx}$ provided by daylight fluorescent tubes. Four commercial grade pesticides: two carbamate pesticides, Furadan and Sevin (Union Carbide Limited, Bangalore, India) and one each of organophosphate and organochlorine, Rogor and Endotaf respectively (Rallis India Limited, Bombay, India) were used in this investigation. Fresh stock solutions of these pesticides were prepared for experiments in sterilized media and added aseptically to the culture media to obtain the desired concentration. The $\mathrm{pH}$ of all of the test media was adjusted to 7.8. Experiments were conducted by inoculating actively growing organisms into $25 \mathrm{ml}$ of culture medium in $100-\mathrm{ml}$ cotton stoppered conical flasks. Growth was estimated on a dry weight basis by the procedure followed earlier(11). Growth was also measured in terms of the absorbancy of acetone extracts in a Systronics Spectrocolorimeter at $660 \mathrm{~nm}$. Total nitrogen fixed by the cyanobacterium in the presence of different concentrations of the pesticides was estimated on the 15th day of incubation. The cultures were subjected to Kjeldahl digestion and total nitrogen was estimated according to Friedrich as modified by Herbert et al.(7). Corrections were made for the nitrogen present in the pesticides.

The survivability of the organism was studied on agar plates containing varying concentrations (10 to $1,500 \mathrm{ppm}$ ) of the pesticides. Samples of $1.0 \mathrm{ml}$ of a diluted suspension of the cyanobacterium were spread aseptically onto each of the agar plates and incubated under light in the culture room. After 10 days of incubation, the colonies were counted under a binocular microscope and the survival data were plotted taking survival on the control plates as $100 \%$. The rate of $\mathrm{O}_{2}$ evolution was measured with a Clark type oxygen electrode (Yellow Spring, Ohio, U.S.A.) and a Hitachi 056 recorder. Cyanobacterial filaments containing approximately 2.0 to $3.0 \mu \mathrm{g}$ of chlorophyll $a$ from the 72 -h-old experimental cultures, containing various concentrations of the pesticides, were transferred to a periglass vessel fitted with an outer jacket for water circulation and temperature maintenance $\left(25^{\circ} \mathrm{C}\right)$ during the experiment. To avoid reduction at the cathode and to maintain a stable oxygen gradient across the membrane, the cyanobacterial suspension was stirred with a magnetic stirrer. Saturating light intensity of $200 \mathrm{~W} \cdot \mathrm{m}^{2}$ was provided by a $150 \mathrm{~W}$ halogen lamp through a heat cut filter $(70 \%)$. The signal from the cathode was fed through a pre-amplifier to increase the efficiency of recording. Chlorophyll $a$ was 
extracted from the cyanobacterial filaments with $80 \%$ acetone and the amount was determined spectrophotometrically using the absorption coefficient of Mackinney (10).

\section{RESULTS AND DISCUSSION}

The effect of four different pesticides on the survival, growth and nitrogen fixation of Westiellopsis prolifica was studied in experiments with 10, 20, 50, 100, $250,500,1,000$, and $1,500 \mathrm{ppm}$ of each pesticide in the culture solution. The results, Tables 1 and 2, indicate a progressive decrease in the growth and nitrogen fixation with increasing concentrations of the pesticides. The carbamate pesticides Furadan and Sevin were less toxic than organophosphate, Rogor or the organochlorine Endotaf. The presence of $1,000 \mathrm{ppm}$ of Furadan and Sevin in the medium were algistatic, but that concentration of Rogor and a still lower concentration of Endotaf were algicidal (Fig. 1). With Rogor the growth remained almost unaffected at $10 \mathrm{ppm}$, but at the same concentrations, the carbamate insecticides actually stimulated the growth. Nitrogen fixation was also increased at these lower doses. Similar enhancement of growth and nitrogen fixation in various other cyanobacterial species in the presence of Furadan (8) and 2,4-D(4) have been reported. At concentrations above $20 \mathrm{ppm}$ of Furadan, Sevin and Rogor, growth and nitrogen fixation progressively declined (Tables 1 and 2). Endotaf was toxic even at $10 \mathrm{ppm}$; at more than $250 \mathrm{ppm}$ the growth and nitrogen fixation stopped completely.

The effect of pesticides on photosynthetic oxygen evolution is shown in Table 3. Incubation of $W$. prolifica for a period of $72 \mathrm{~h}$ in the presence of varying concentrations of pesticides and determination of the rate of photosynthesis thereafter (in terms of $\mu \mathrm{mol} \mathrm{O}_{2 \text { evolved }} \cdot \mathrm{mg}$ chlorophyll $a^{-1} \cdot \mathrm{h}^{-1}$ ) showed that this process was inhibited by all the tested pesticides. Exposure of the filaments to Sevin at a dose of $10,50,100,250,500$, and $1,000 \mathrm{ppm}$ inhibited photosynthetic oxygen evolution $5.3,25.8,41.9,61.0,88.0$, and $100 \%$ respectively. The commercial grade Furadan was less toxic to the organism than Sevin (Table 3). Oxygen evolution was completely suppressed on exposure to over $500 \mathrm{ppm}$ of Rogor. The toxic effect of Endotaf on the photosynthetic oxygen evolution was more pronounced. Even at only $10 \mathrm{ppm}$, the oxygen evolution rate was reduced by $22.5 \%$ and it was completely suppressed at more than $250 \mathrm{ppm}$ (Table 3 ). These results accord with the changes in the morphology of $W$. prolifica filaments exposed to pesticides. In the presence of more than $250 \mathrm{ppm}$ of Furadan, Sevin and Rogor and $100 \mathrm{ppm}$ of Endotaf, the erect branches of the filaments were suppressed and the number of heterocysts per filament decreased even to a larger extent. This shows that higher concentrations of pesticides decrease the survivability, growth and nitrogen fixation of rice-field nitrogen-fixing cyanobacteria. The toxic dose of organophosphate and carbamate pesticides in these experiments was $>10 \mathrm{ppm}$, so the lower concentrations may not affect the growth and nitrogen fixation of cyanobacteria under field conditions. 


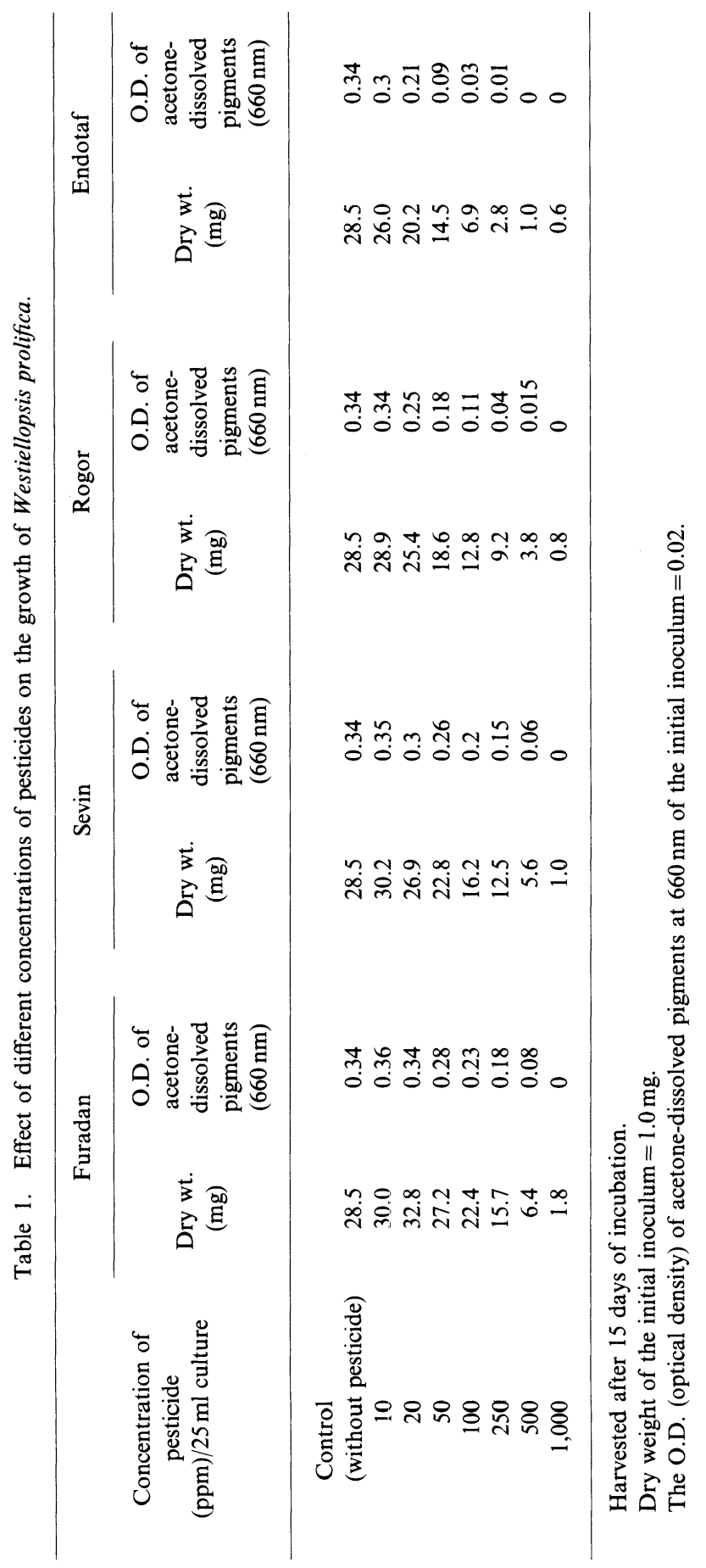


Table 2. Effect of different concentrations of pesticides on the total nitrogen fixed ( $\mathrm{mg} / 25 \mathrm{ml}$ culture) by Westiellopsis prolifica harvested after 15 days of incubation.

\begin{tabular}{clllll}
\hline $\begin{array}{c}\text { Concentration } \\
\text { of pesticide } \\
(\mathrm{ppm})\end{array}$ & Furadan & Sevin & Rogor & Endotaf \\
\hline 0 (control) & 3.6 & & 3.6 & 3.6 & 3.6 \\
10 & $3.8(+5.5)$ & $3.5(+2.7)$ & $3.8(+5.5)$ & $1.7(-52.7)$ \\
20 & $3.4(-5.5)$ & $3.2(-11.1)$ & $2.7(-25.0)$ & $1.1(-69.4)$ \\
50 & $2.8(-22.2)$ & $2.2(-38.8)$ & $2.0(-44.4)$ & $0.83(-79.6)$ \\
100 & $2.0(-44.4)$ & $1.5(-58.3)$ & $0.9(-74.7)$ & $0.25(-93.0)$ \\
250 & $1.6(-55.5)$ & $0.96(-73.3)$ & $0.33(-90.8)$ & 0 \\
500 & $0.83(-76.9)$ & $0.45(-87.5)$ & $0.1(-97.2)$ & 0 \\
1,000 & 0 & 0 & 0 & & 0
\end{tabular}

Figures in parenthesis show the percentage increase or decrease relative to the nitrogen fixation in the control.

+ , percentage increase; - , percentage decrease.

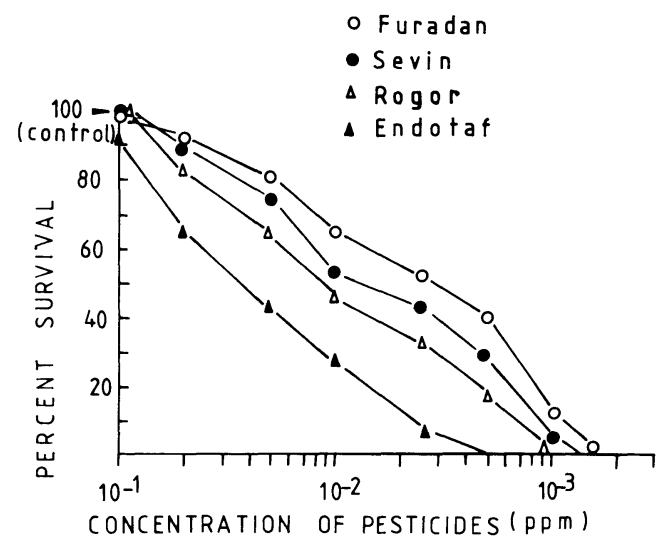

Fig. 1. Percentage survival of Westiellopsis prolifica in the presence of different concentrations of pesticides in the medium. Cultures were incubated at $28 \pm 2{ }^{\circ} \mathrm{C}$ under $2,400 \mathrm{~lx}$ light intensity for 15 days.

But at higher concentrations ( $>50 \mathrm{ppm}$ ) the nitrogen fixing ability of cyanobacteria decreased considerably, so excessive use of these pesticides may well affect the overall nitrogen economy of rice-field soils. The organochlorine pesticides are especially more toxic; at $>10 \mathrm{ppm}$ they affected $W$. prolifica adversely, so they may also adversely affect the survivability of a variety of microorganisms in nature. Therefore, caution should be taken to determine the appropriate application dosage of these environmental pollutants before applying them in rice-fields and other aquatic ecosystems. 
Table 3. Effect of different concentrations of pesticides on photosynthesis in Westiellopsis prolifica.

\begin{tabular}{ccccc}
\hline \multirow{2}{*}{$\begin{array}{c}\text { Concentration } \\
\text { of pesticide } \\
(\mathrm{ppm})\end{array}$} & Furadan & Sevin & Rogor & Endotaf \\
\cline { 2 - 5 } & 186 & 186 & 186 & 186 \\
\hline $0($ control) & $182(2.15)$ & $176(5.3)$ & $170(8.6)$ & $144(22.5)$ \\
10 & $154(17.2)$ & $138(25.8)$ & $124(33.3)$ & $98.5(47.0)$ \\
50 & $112(39.7)$ & $108(41.9)$ & $96.4(48.1)$ & $33.2(82.1)$ \\
100 & $76.6(58.8)$ & $72.4(61.0)$ & $48.3(74.0)$ & $12.2(93.4)$ \\
250 & $44.1(76.2)$ & $22.2(88.0)$ & $7.4(96.1)$ & $0(100)$ \\
500 & & & & \\
\end{tabular}

The organism was incubated in the presence of pesticides for a period of $72 \mathrm{~h}$; then the rate of photosynthesis was determined.

Figures in parenthesis show the percentage inhibition of photosynthetic oxygen evolution in the presence of pesticides.

Financial support for this work by the University Grants Commission, New Delhi is gratefully acknowledged.

\section{REFERENCES}

1) Adhikary, S. P., Dash, P., and Pattnaik, H., Effect of the carbamate insecticide Sevin on Anabaena sp. and Westiellopsis prolifica. Acta Microbiol. Hung., 31, 335-338 (1984).

2) Allen, M. B. and Arnon, D. I., Studies on nitrogen-fixing blue-green algae. I. Growth and nitrogen fixation by Anabaena cylindrica Lemm. Plant Physiol., 30, 366-372 (1955).

3) Armstrong, T. F., Willium, F. M., and Donald, P., Yellow nutsedge control with Alachlor. Weed Sci., 21, 354-357 (1973).

4) Das, B. and Singh, P. K., Effect of 2,4-dichlorophenoxy acetic acid on growth and nitrogen fixation of blue-green alga Anabaena raciborskii. Arch. Environ. Contam. Toxicol., 5, 437-445 (1977).

5) Fogg, G. E., Growth and heterocyst production in Anabaena cylindrica Lemm. II. In relation to carbon and nitrogen metabolism. Ann. Bot., 13, 241-259 (1949).

6) Geike, F. and Parasher, C. D., Effect of hexachlorobenzene (HCB) on photosynthetic oxygen evolution and respiration of Chlorella pyrenoidosa. Bull. Environ. Contam. Toxicol., 20, 647-651 (1978).

7) Herbert, D., Phipps, P. J., and Strange, R. E., Chemical analysis of microbial cells. In Methods in Microbiology, Vol. 5B, ed. by Norris, J. R. and Ribbons, N. W., Academic Press, New York (1971), p. 210-344.

8) Kar, S. and Singh, P. K., Toxicity of carbofuran to blue-green alga Nostoc muscorum. Bull. Environ. Contam. Toxicol., 20, 707-714 (1978).

9) Lal, R. and Saxena, D. M., Accumulation, metabolism and effects of organochlorine insecticides on microorganisms. Microbiol. Rev., 46, 95-127 (1982).

10) Mackinney, G., Absorption of light by chlorophyll solution. J. Biol. Chem., 140, 315-322(1941).

11) Sahu, J. and Adhikary, S. P., Heterotrophic growth and pigment composition of four filamentous blue-green algae. Arch. Hydrobiol., 63, 189-199 (1982).

12) Singh, H. N. and Vaishampayan, A., Biological effects of rice-field herbicide Machete on various strains of the nitrogen fixing blue-green alga Nostoc muscorum. Environ. Exp. Bot., 18, 87-94 (1978). 
13) Snyder, C. E. and Sheridan, R. P., Toxicity of the pesticide Zectron on photosynthesis, respiration and growth in four algae. J. Phycol., 10, 137-139 (1974).

14) Venkataraman, G. S., Algal Biofertilizer and Rice Cultivation. Today and Tomorrows Printers and Publishers, New Delhi (1972), p. 20-22. 